\title{
EDUCAÇÃO ESPECIAL NO MUNICÍPIO DE SOROCABA, SP: OS CONTEXTOS DAS POLÍTICAS E O DIREITO À EDUCAÇÃO
}

\author{
Patricia Lopes Ramos Públio ${ }^{1}$ \\ Paulo Gomes Lima ${ }^{1}$ \\ Katia Regina Moreno Caiado ${ }^{1}$
}

RESUMO: Este estudo teve como objetivo investigar a atual estrutura organizativa e os serviços de educaçáo especial nas escolas públicas e nas instituiçóes especializadas credenciadas como escolas que funcionam no município de Sorocaba, São Paulo; bem como apresentar a análise do contexto das políticas de educaçáo especial na rede municipal, no período de 1988 a 2016, buscando compreender as produçôes e negociaçôes que, permeadas pelos seus significados, atuam na garantia do direito à educaçấo. A pesquisa é embasada pela abordagem do ciclo de política, formulada por Stephen Ball, que destaca a natureza complexa e controversa da política educacional. Os resultados revelam que as escolas especiais privadas, com recursos públicos, detêm o maior número de matrículas dos estudantes com deficiência e transtornos globais do desenvolvimento. $\mathrm{Na}$ rede municipal, a política de educaçáo especial buscou ajustar-se às configuraçóes das políticas nacionais e internacionais, mostrando o quanto o contexto de influência (BALL, 2001; BALL; MAINARDES, 2011) foi determinante. Em cada período, as açôes desenvolvidas pela Secretaria Municipal da Educação foram se modificando, fundadas nos diferentes projetos governamentais. No entanto, por não se consolidarem como uma política pública municipal, evidenciam processos de rupturas no direito à educação dos estudantes público-alvo da educação especial.

Palavras-chave: Educaçáo especial. Políticas públicas. Direito à educação.

${ }^{1}$ Universidade Federal de São Carlos - São Carlos (SP), Brasil. E-mails: patricia.patriciapublio@gmail.com, caiado.katia@gmail.com, paulolima@ufscar.br DOI: 10.1590/CC0101-32622018198957 


\section{Special education in the municipality of Sorocaba, SP, Brazil: the contexts of policies and the right to education}

ABSTRACT: This study aims to investigate the current organizational structure and special education services in public schools and specialized institutions certified as schools operating in Sorocaba, SP, as well as to present the analysis of the context of special education policies in the municipal education system, from 1988 to 2016, seeking to understand the production and negotiations pervaded by their purpose of guaranteeing the right to education. The research is based on the approach of the political cycle, formulated by Stephen Ball, which emphasizes the complex and controversial nature of educational policy, proposing the existence of a political cycle. The results show that private, however, publicly- funded, special schools, hold the highest enrollments of students with disabilities and overall development disorders. In the municipal education system, special education policy sought to adjust to national and international policy settings, demonstrating how influential the context (BALL, 2001; BALL; MAINARDES, 2011) was. In each period, the actions developed by the municipal office of education were modified with the foundation of its governmental projects; however, as they were not able to consolidate as a municipal public policy, they evidenced processes of ruptures.

Keywords: Special education. Public policies. The right to education.

\section{INTRODUÇÃO}

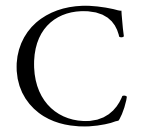

oncretizar o que é preconizado pelas políticas públicas nacionais de educação especial representa o enfrentamento de inúmeros desafios aos municípios brasileiros para a garantia do direito à educação.

Mesmo com um aparato legal dessas garantias, a perspectiva histórica nos revela um processo permeado por significativas rupturas e avanços em que permanecem percursos de exclusão social e escolar. 
Para Saviani, se a educação é proclamada e reconhecida como direito, cabe ao poder público a responsabilidade de criar meios para sua efetivação. Entretanto, historicamente, a política nacional brasileira vem sendo marcada pela resistência aos investimentos educacionais no país. Somado a essa realidade, o Estado sustenta os recursos à filantropia e ao voluntariado e, dessa forma, repassa à sociedade civil responsabilidades e incumbências que seriam dele ocasionando, assim, o fortalecimento da iniciativa privada, conforme pode ser observado nos últimos anos (SAVIANI, 2013). Essas questóes aparecem de forma transversal no município de Sorocaba, como um recorte da política nacional, logo, o direito que deveria ser encaminhado por força da agenda, da formulação do texto da política e sua respectiva implementação se reduz à um conjunto de estado de coisas que é anterior a própria razão da política pública requerendo, não raras vezes, encaminhamentos via judicialização para se fazer valer o direito.

Indicadores oficiais revelam uma evolução significativa no número das matrículas de estudantes que são público-alvo da educação especial nas escolas comuns. Porém, pesquisas mostram que, Brasil afora, a maioria dessas matrículas é de estudantes com deficiência intelectual (GOÉS, 2014), enredados numa trama histórica de produção do fracasso escolar (PATTO, 1999).

Em 2007, dados referentes aos beneficiários do Programa Benefício de Prestação Continuada (BPC) mostraram que 79\% dos beneficiários com deficiência em idade escolar estavam fora da escola (CAIADO et al., 2014). Outros estudos têm analisado o fluxo escolar e a distorção entre idade e série dos estudantes com deficiência e os resultados mostram fluxos escolares interrompidos e largo abandono da escola (MELLETTI; RIBEIRO, 2014; MACALLI, 2013).

À vista disso, compreendemos as políticas públicas educacionais segundo as fundamentaçóes de Stephen Ball (BALL, 2001; BALL; MAINARDES, 2011) como processos complexos, uma vez que os textos das políticas não são simplesmente transpostos para a realidade com sentidos fixos e imutáveis, mas, sim, reinterpretados pelos sujeitos em seus contextos.

Para Ball (2001), as políticas configuram-se no tempo e no espaço por meio de um jogo de disputas e interesses, estabelecido em um ciclo 
de políticas que considera diferentes contextos com características próprias, complexidades e interdependência. De acordo com o autor, as políticas, além de se constituírem em processos e consequências, também são texto e discurso, duas concepçôes que se complementam e estão implícitas.

Desse modo, cria-se uma dimensão em que as políticas, referenciadas como contextos, movimentam-se entre consensos e conflitos.

A partir desse quadro de realidade e de fundamentos, analisamos a trajetória histórica das produçóes das políticas públicas de educação especial na rede municipal de Sorocaba, interior do estado de Sáo Paulo, buscando compreender os principais desafios encontrados para a garantia do direito à escolarização dos estudantes público-alvo da educação especial, bem como as permanências e rupturas das políticas constituídas pelo município.

\section{MUNICÍPIO DE SOROCABA/SP}

O município de Sorocaba está localizado na Regiáo Sudoeste do estado de São Paulo, distante cerca de $90 \mathrm{~km}$ da capital paulista, com população, no ano de 2016, de 652.481 pessoas.

Sorocaba apresenta um Produto Interno Bruto (PIB) de $\mathrm{R} \$ 16,12$ bilhóes e a base de sua economia está distribuída entre os cinco setores. O comércio e a indústria, juntos, representam $51,26 \%$ da economia local e os serviços, $42,58 \%$.

Entretanto, ao analisar a distribuiçáo de renda, podemos afirmar que, mesmo o município tendo um alto PIB que retrata seu crescimento econômico, as desigualdades sociais existentes são grandes, fato que pode ser confirmado quando constatamos que aproximadamente $70 \%$ da população sobrevive com até dois salários mínimos mensais (IBGE, 2010).

Sobre a organização política partidária, desde o golpe militar no país o município e o estado mantém uma simetria eleitoral dos partidos Aliança Renovadora Nacional (Arena), Partido do Movimento Democrático Brasileiro (PMDB) e Partido da Social Democracia 
Brasileira (PSDB), estando esse último há mais de vinte anos no poder. Essa simetria partidária nos mostra que os planos e agendas do governo estadual e municipal se aproximam na manutenção de um projeto de sociedade articulado com o ideário liberal e neoliberal. Esse, conduz as decisões nas políticas públicas para a educação e a educação especial.

Centrado no modelo sistêmico de políticas públicas, onde a influência supranacioncal tem considerável impacto nas políticas nacionais, o Estado brasileiro encaminha políticas públicas dentre de contornos específicos e reduzidos, conforme o grau de priorização e visibilidade, previstos em acordos multilaterais. Nesse contexto de influência, conforme destacam Ball (2001) e Ball e Mainardes (2011), as políticas subnacionais (estaduais) e locais são também contempladas. Logo, o contexto da produçáo do texto político, articulado ao contexto da prática por meio de projetos, programas, estratégias e açóes estabelecem parâmetros delimitados, nesse caso, à lógica hegemônica do capital, ou seja, a dimensão neoliberal. Com efeito, por conta do recorte do objeto, tais contextos serão eixos de recorrência nas seçóes a seguir.

\section{EDUCAÇÃO E EDUCAÇÃO ESPECIAL NO MUNICÍPIO DE SOROCABA}

A fim de compor o contexto municipal, no que diz respeito aos indicadores educacionais, podemos verificar, com base nos dados do Instituto Brasileiro de Geografia e Estatística (IBGE, 2010), que 99,09\% das pessoas de 10 a 17 anos de idade residentes no município estáo alfabetizadas.

Trazemos, nas Tabelas 1 e 2, os números de matrículas dos estudantes na educação básica e na educação especial na educação básica nas esferas: federal, estadual e municipal.

Verificamos, nesses dados do Censo Escolar, tanto a nível federal quanto estadual, uma redução do número de matrículas dos estudantes na educação básica, embora no município esse sentido seja inverso. Já nos números de matrículas dos estudantes público-alvo da educação especial houve um crescimento na esfera federal e municipal enquanto, se analisarmos apenas na esfera estadual, houve redução. 
A fim de qualificar os dados, a Tabela 3 mostra os números de matrículas dos estudantes público-alvo da educação especial nas redes investigadas no município de Sorocaba em 2016.

Diante desses dados, podemos constatar que a rede privada, nas instituiçóes especializadas certificadas como escolas de educaçâo especial, detém o maior número das matrículas do município.

\section{Tabela 1}

Número de matrículas dos estudantes na educação básica.

\begin{tabular}{l|c|c|c}
\hline Ano & Brasil & Sáo Paulo & Sorocaba \\
\hline 2010 & 51.549 .889 & 10.729 .290 & 157.428 \\
\hline 2013 & 50.042 .448 & 10.327 .057 & 160.460 \\
\hline 2015 & 48.796 .512 & 10.101 .834 & 160.876 \\
\hline
\end{tabular}

Fonte: com base em dados do Instituto Nacional de Estudos

e Pesquisas Educacionais Anisio Teixeira (INEP, 2017).

\section{Tabela 2}

Número de matrículas dos estudantes da educação especial na educação básica.

\begin{tabular}{l|c|c|c}
\hline Ano & Brasil & Sáo Paulo & Sorocaba \\
\hline 2010 & 702.603 & 198.775 & 2.171 \\
\hline 2013 & 843.342 & 174.200 & 2.177 \\
\hline 2015 & 930.683 & 167.251 & 2.279 \\
\hline
\end{tabular}

Fonte: com base em dados do Instituto Nacional de Estudos e Pesquisas Educacionais Anisio Teixeira (INEP, 2017).

\section{Tabela 3}

Número de matrículas dos estudantes da educação especial em 2016.

\begin{tabular}{l|c|c}
\hline Rede municipal & Rede estadual & $\begin{array}{c}\text { Rede privada - escolas } \\
\text { de educaçáo especial }\end{array}$ \\
\hline 503 & 589 & 703 \\
\hline
\end{tabular}

Fonte: com base em dados do Instituto Nacional de Estudos e Pesquisas Educacionais Anisio Teixeira (INEP, 2017). 


\section{EDUCAÇÃO ESPECIAL NA REDE PRIVADA}

Em 2016, Sorocaba tinha um total de 13 instituiçóes especializadas na área, dentre as quais sete estavam credenciadas como Escolas de Educação Especial, recebendo subvenção mensal dos poderes públicos, estadual e/ou municipal, configurando uma parceria de convênios por meio da oferta de vagas e bolsas de estudos (PÚBLIO, 2016).

Para compreensão desse panorama apresentamos, na Tabela 4, a configuração dos atendimentos.

\section{Tabela 4}

Escolas de educação especial (Rede Privada) em Sorocaba em 2016.

\begin{tabular}{|c|c|c|c|c|c|c|}
\hline Instituiçáo & $\begin{array}{l}\text { Ano de } \\
\text { fundaçáo }\end{array}$ & $\begin{array}{l}\text { Público- } \\
\text { alvo }\end{array}$ & $\begin{array}{l}\text { Número } \\
\text { de pessoas } \\
\text { atendidas }\end{array}$ & $\begin{array}{c}\text { Número de } \\
\text { matricu- } \\
\text { ladas na } \\
\text { escola }\end{array}$ & \begin{tabular}{|c} 
Número \\
de pessoas \\
atendidas na \\
assistência \\
social
\end{tabular} & $\begin{array}{l}\text { Número } \\
\text { de pessoas } \\
\text { atendidas } \\
\text { na saúde }\end{array}$ \\
\hline APAE & 1967 & $\begin{array}{l}\text { Deficiência } \\
\text { Intelectual } \\
\text { e Múltiplas }\end{array}$ & 350 & 150 & 129 & 71 \\
\hline $\begin{array}{l}\text { Associação } \\
\text { PRÓ EX }\end{array}$ & 1983 & $\begin{array}{l}\text { Deficiência } \\
\text { Intelectual } \\
\text { e Múltiplas }\end{array}$ & 111 & 75 & 36 & \\
\hline $\begin{array}{l}\text { Fundação } \\
\text { Melanie } \\
\text { Klein }\end{array}$ & 1991 & $\begin{array}{l}\text { Deficiência } \\
\text { Intelectual } \\
\text { e Múltiplas }\end{array}$ & 75 & 75 & & \\
\hline Integrar & 1993 & $\begin{array}{l}\text { Paralisia } \\
\text { Cerebral }\end{array}$ & 185 & 49 & 136 & \\
\hline $\begin{array}{l}\text { Instituição } \\
\text { Clave de } \\
\text { Sol }\end{array}$ & 1993 & $\begin{array}{c}\text { Deficiência } \\
\text { Intelectual, } \\
\text { Múltiplas e } \\
\text { Autismo }\end{array}$ & 307 & 307 & & \\
\hline AMAS & 1994 & $\begin{array}{c}\text { Autismo e } \\
\text { Síndrome } \\
\text { de Rett }\end{array}$ & 94 & 47 & 47 & \\
\hline $\begin{array}{l}\text { Associação } \\
\text { Santa Rita }\end{array}$ & 1997 & $\begin{array}{l}\text { Deficiência } \\
\text { Intelectual }\end{array}$ & 149 & & & \\
\hline Total & & & 1271 & 703 & 348 & 71 \\
\hline
\end{tabular}

Fonte: com base em dados obtidos nas instituiçôes em 2016. 
Podemos constatar que faz cinco décadas que a rede privada de instituiçóes especializadas oferta e consolida seus trabalhos no município, com significativa expansão na década de 1990.

\section{EDUCAÇÃO ESPECIAL NA REDE ESTADUAL}

As ações desenvolvidas na Rede Estadual de São Paulo estão definidas pela Resolução SE 61, de 11.11.2014, que entrou em vigor em janeiro de 2015. Porém, é importante destacar que, desde $1995^{1}$, houve liberação de crescentes repasses de verbas às instituiçốes especializadas na área da educação especial (LAPLANE; CAIADO; KASSAR, 2016).

Em 2016, a rede estadual contava com um total de 85 escolas de educação básica e ensino médio, somando 58.450 matrículas, sendo 589 de estudantes público-alvo da educação especial, o que representava $1,007 \%$ das matrículas totais.

A equipe responsável pela educação especial da Diretoria de Ensino estava composta por três supervisores e dois professores coordenadores que trabalhavam em parceria com o Centro de Atendimento Especializado (CAPE) e com o Núcleo de Apoio Pedagógico Especializado.

No CAPE, o trabalho era desenvolvido por equipe multidiscilinar, formada por psicólogo, terapeuta ocupacional, fonoaudióloga e psicopedagoga. O CAPE é sediado na Diretoria de Ensino de Sorocaba que, no ano em que a pesquisa foi desenvolvida, atendia um total de oito diretorias e cujo quadro de profissionais era composto de 23 professores especialistas, 28 professores interlocutores, 41 cuidadores e 18 professores auxiliares. O cenário da rede estadual era composto por 23 salas de recursos e contava com 210 estudantes matriculados. As salas e os profissionais eram organizados para o atendimento específico por área da deficiência.

Sobre o total de estudantes matriculados como público-alvo da educação especial, 35,6\% frequentavam o serviço oferecido nas salas de recurso, ou seja, menos da metade dos estudantes. 


\section{EDUCAÇÃO ESPECIAL NA REDE MUNICIPAL}

Apresentaremos um breve panorama dos movimentos das políticas de educação especial na rede municipal após a Constituição Federal de 1988, em cinco períodos organizados a partir da produção de documentos legislativos considerados como marcos políticos para a educação especial.

\section{MOVIMENTOS HISTÓRICOS E POLÍTICOS: PERÍODO DE 1991 A 1996}

O primeiro documento encontrado nesse período foi a Lei 3601 de 1991, que dispunha sobre o atendimento educacional especializado aos portadores de deficiências físicas e mentais e determinava a implantação de pelo menos uma classe de educação especial em cada escola municipal (SOROCABA, 1991). Em atendimento a essa lei, no ano de 1992 foi criada a primeira classe especial para "deficientes mentais educáveis".

Em 1993, o município estabeleceu um convênio com a Universidade Estadual de Campinas (Unicamp), assessorado pela profa. Dra. Maria Teresa Eglér Mantoan, com o início da formação de professores para a integração dos estudantes com deficiência mental. Ainda nesse ano, foi criada uma classe especial para estudantes com deficiência auditiva e se determinou que cada escola da rede atenderia, preferencialmente, um tipo de deficiência (PÚBLIO, 2016).

Além das classes especiais, a secretaria contava com um serviço de psicólogos para atendimento e acompanhamento dos estudantes integrados na rede e, em 1995, foi criada uma Diretoria de Educação Especial.

Para o ensino fundamental, criou-se um regimento único para as unidades escolares que garantia a reserva de $5 \%$ do número de vagas a estudantes com deficiência. Por meio desse documento, a secretaria procurava garantir o acesso e a escolarizaçáo dos estudantes com deficiência com a expectativa de que essa integração provocaria, 
nos profissionais da escola, a tomada de consciência a respeito da necessidade de mudança com relação à estrutura e às concepçóes de prática pedagógica e, assim, deflagraria a construção de uma educação feita pelo coletivo (PEREZ, 2001, p. 66).

Esse período revelou evidências de ruptura no sistema educacional vigente, marcadas por açóes que tiveram como finalidade a busca pela efetivação de políticas favorecedoras da escolarização dos estudantes público-alvo da educação especial e de açóes permanentes. Tais açóes refletiram na progressão do número de matrículas dos estudantes com deficiência no ensino regular. No contexto da produção do texto e da implementação (prática), ainda que importante, nesse momento ainda era pouco representativo, visto a incipiência da medida legal e da insuficiência dos recursos destinados a tal finalidade.

\section{MOVIMENTOS HISTÓRICOS E POLÍTICOS: PERÍODO DE 1997 A 2001}

Após a aprovação da Lei de Diretrizes e Bases da Educação Nacional, em 1996, foi aprovada, no município, a Lei no 5.413, de 1997, que estabelecia normas para o ingresso das pessoas com deficiência na rede regular de ensino municipal e destinava $10 \%$ das vagas existentes para esse público, na intenção de garantir o acesso à escola (SOROCABA, 1997).

$\mathrm{Na}$ busca da efetivação da premissa de uma educação para todos, a Diretoria de Educação Especial, até então responsável pela integração dos estudantes com deficiência nas escolas regulares, foi destituída mantendo-se a Seção de Educação Especial.

Nesse processo de reorganização, as classes especiais foram fechadas e os estudantes passaram a frequentar o ensino regular. Apesar da resistência das famílias e dos profissionais das escolas, a secretaria persistiu nessa decisão e ofereceu o serviço de apoio pedagógico com professores itinerantes (PÚBLIO, 2016).

Em 1999, aconteceu a extinção da Seção de Educação Especial e a equipe passou a compor a Seção de Planejamento e Apoio Pedagógico da Educação Básica, denominada de equipe de apoio pedagógico. 
Diante da necessidade em esclarecer qual era o projeto político de educação da rede, a Secretaria da Educação e Cultura divulgou as Diretrizes Pedagógicas para Gestão Democrática na Escola, que tinha como objetivo oferecer uma educação de qualidade para todos fundamentada em três princípios norteadores: Educação Inclusiva, Educação Humanista e Gestão Democrática.

Muitos movimentos consolidaram a construção histórica e social desse período. Pode-se destacar o fechamento das classes especiais como um desses marcos. Com essa decisão, acreditava-se que os estudantes seriam incluídos nas escolas e teriam atendidas suas diversidades de aprendizagem por meio de práticas pedagógicas adaptadas à nova realidade que se configurava no sistema de ensino.

Para tanto, pode-se verificar que as açóes políticas desenvolvidas e propostas pela secretaria empreenderam discussóes, orientaçóes e ações formativas junto aos profissionais das escolas, o que possibilitou estudos e discussóes sobre o contexto da prática escolar. Entretanto, mesmo sendo essa ação uma condição fundamental para o novo projeto de escola, a ousadia e o compromisso dos profissionais da secretaria na busca de uma escola que garantisse o direito à educação para todos, sem alcance de um amplo projeto político, não foram suficientes.

Dessa maneira, finalizou-se esse período até o ano de 2001, balizado pela Resolução no 02/2001 — Diretrizes Nacionais para a Educação Especial na Educação Básica e o Plano Nacional de Educação.

\section{MARCOS HISTÓRICOS E POLÍTICOS: PERÍODO DE 2002 A 2008}

Ao final do ano de 2002, terminaram os dez anos de assessoria da Profa. Maria Tereza Eglér Mantoan junto à rede municipal, onde permaneceu o trabalho desenvolvido pelas equipes da secretaria pautadas nos Projetos Políticos Pedagógicos das escolas.

Em 2007, foi implementado o programa Cidade Educadora, mediante um plano de cooperação técnica entre o Governo Brasileiro e a Organização das Naçóes Unidas para a Educação, Ciência e Cultura (Unesco). Esse programa, segundo os estudos de Santos, concretizou-se 
na cidade por meio de inúmeros e diferentes projetos com altos investimentos financeiros (SANTOS, 2009). Entretanto, podemos verificar que nenhum projeto contido no programa evidenciava questóes acerca das especificidades da educação especial.

Porém, com o crescimento da rede municipal, as solicitações relacionadas às áreas sociais, pedagógicas e especializadas se intensificaram, forçando a necessidade de serviços e de profissionais para atendimento às necessidades educacionais dos estudantes. Assim, pressionada, a secretaria retomou o projeto de construção de um Centro de Referência em Educação para a garantia do direito de aprendizagem do público-alvo da educação especial.

A primeira aproximação da Secretaria de Educação (SEDU) com o Instituto Paradigma ${ }^{2}$ (IP) aconteceu no ano de 2006, quando a equipe técnica visitou o Centro de Atençáo ao Desenvolvimento Educacional (CADE), recurso da Secretaria de Educação do município de Santo André e, ali, conheceu o programa de educação inclusiva desenvolvido em parceria com o Instituto. Na sequência, foi aprovada uma proposta para Sorocaba, com destaque para a criação do Centro de Referência em Educação (CRE), como um serviço de atenção e atendimento aos estudantes com deficiência matriculados nas escolas municipais.

A ruptura da assessoria técnica com a Unicamp, direcionada à Educação Especial, e o início de um novo governo regulado por açóes políticas que se consolidaram por meio de novas assessorias e consultorias privadas são as marcas desse terceiro período. À vista dos projetos implementados, o governo trouxe como determinante um discurso de excelência, efetividade e de oferta de uma educação de qualidade denotando, somente no final do período, a necessidade e efetividade da construção do CRE.

\section{MARCOS HISTÓRICOS E POLÍTICOS: PERÍODO DE 2009 A 2012}

Esse período é delimitado pelo encerramento do período anterior, em 2008, quando foi publicada a Política Nacional de Educação Especial na Perspectiva da Educaçáo Inclusiva e houve uma nova proposta de governo em decorrência das eleiçóes municipais. 
Em 2009 foi inaugurado o CRE com vistas a promover e a garantir o princípio de educação de qualidade para todos, com foco no processo de aprendizagem por meio de assessoria multidisciplinar aos espaços educacionais (SOROCABA, 2008).

A equipe foi caracterizada como multidisciplinar, formada por pedagogos e especialistas (psicólogos, fisioterapeutas, fonoaudiólogos, terapeutas ocupacionais e assistentes sociais).

A estrutura para o desenvolvimento dos trabalhos estava organizada por categorias, denominadas como demandas: pedagógica, social e especializada. Eram considerados como demanda pedagógica os estudantes com dificuldades de aprendizagem; como demanda social os estudantes em situação de vulnerabilidade social ou violência; e, como demanda especializada, os atendimentos com profissionais especialistas que compóem a equipe (SOROCABA, 2009).

Os trabalhos foram estruturados a partir dos seguintes macroprocessos: processo de itinerância (visita dos professores nas escolas para orientaçóes pedagógicas e coleta das demandas para os especialistas); processo de atendimento dos polos no CRE (divisão das escolas por polos para atendimento da equipe multidisciplinar); processo de atendimento dos estudantes no CRE (triagem dos alunos para encaminhamentos à rede de parceiros e orientaçóes para as escolas); processo de formação de equipe (formação continuada).

No ano de 2010, iniciou-se o processo de implantação das salas de recursos multifuncionais (SRM), provenientes do Programa Educação Inclusiva: Direito à Diversidade, da Secretaria de Educação Especial do Ministério da Educação (SOROCABA, 2010).

Em 2011, o desenvolvimento do trabalho do CRE com a assessoria do IP teve continuidade na mesma estrutura, porém acrescidos pela reorganização da Matriz Curricular e implementação do Projeto da Recuperação Paralela. (SOROCABA, 2011).

Em 2012, o contrato com o IP foi rompido e as gestoras do CRE, junto à equipe multidisciplinar, elaboraram uma nova proposta de trabalho cujo foco foi o desenvolvimento dos estudantes e sua aprendizagem.

O funcionamento do trabalho foi reorganizado para que os atendimentos fossem realizados de forma multidisciplinar, isto é, com a 
participação conjunta dos especialistas e dos professores, com o propósito de fortalecer as equipes escolares e as famílias (SOROCABA, 2012).

No ano de 2012, foi inaugurada a classe hospitalar em parceria com o hospital Grupo de Pesquisa e Apoio ao Câncer Infantil (GPACI), com o objetivo de desenvolver e acompanhar o trabalho pedagógico junto às crianças e aos jovens com dificuldades graves de saúde e que estão por tempo definitivo ou temporário impedidos de frequentar a escola comum (SOROCABA, 2012).

Assim encerra-se esse período, marcado pela criação, estruturaçâo e funcionamento do CRE. Destaca-se, portanto, que conquistas importantes foram garantidas aos estudantes público-alvo da educaçáo especial, como as salas de recursos multifuncionais, a classe hospitalar, a atuação da equipe multidisciplinar junto às unidades escolares e a continuidade dos processos de formação aos profissionais da educação.

\section{MARCOS HISTÓRICOS E POLÍTICOS: PERÍODO DE 2013 A 2016}

Em decorrência das eleiçóes municipais em 2012, e mesmo com a continuidade do partido político, esse período foi marcado por profundas mudanças na organização e concepção da educação especial no município.

O período se iniciou com uma nova proposta de trabalho pautada em uma lógica governamental de divisão do atendimento das secretarias municipais em regióes da cidade.

Dessa forma, o trabalho do CRE, órgão responsável pela educação especial, se ajustava a essa nova ordem setorial e as equipes multidisciplinares passaram a desenvolver seus trabalhos em todos os níveis de ensino e em de serviços por meio de reunióes que continuam sendo denominadas por Atendimento Multidisciplinar Especializado (AMEs), porém, com uma nova concepção, não mais a pautada no encaminhamento. Os objetivos do CRE foram redefinidos tendo como eixo o desenvolvimento e a aprendizagem dos estudantes por meio da interlocução dos diferentes setores na perspectiva de um contexto aberto ao exercício das diferenças (SOROCABA, 2013). 
Entretanto, essas organizaçóes e trabalhos não se mantiveram permanentes. Foram rearranjadas a cada ano, ora pela busca da qualificação do trabalho desenvolvido pela equipe multidisciplinar, que se mantinha desde a criação do Centro de Referência, ora para atender aos interesses da administração.

Outro fato que marcou o período foi a reorganização no organograma da SEDU, ocasião em que a educação especial passou a ser gestada por uma Divisão e o Centro de Referência foi reconfigurado, passando a comportar outros projetos e programas da Secretaria. Nessa organização, a equipe multidisciplinar também sofreu modificaçóes e os professores formadores e itinerantes deixaram de compor o trabalho.

No ano de 2016, a rede municipal era formada por 163 unidades escolares, sendo 95 de educação infantil, 42 de ensino fundamental, 22 de educação infantil e ensino fundamental e quatro de ensino fundamental e médio.

Com relação às matrículas podemos analisar, segundo os dados das Tabelas 5 e 6, que no período houve um crescimento tanto nas matrículas da educação básica, quanto nas da educação especial. Entretanto, quando cotejamos os dados constatamos, nos três anos analisados, que as matrículas dos estudantes público-alvo da educação especial representam menos de $1 \%$ do número de matrículas gerais no município.

\section{Tabela 5}

Número de matrículas na educação básica da rede municipal no período de 2013 a 2015.

\begin{tabular}{|c|c|c|c|c|c|c|c|}
\hline \multirow{3}{*}{ Ano } & \multicolumn{6}{|c|}{ Ensino regular } & \multirow{3}{*}{ Total } \\
\hline & \multicolumn{2}{|c|}{ Educação infantil } & \multicolumn{2}{|c|}{ Ensino fundamental } & \multirow{2}{*}{$\begin{array}{c}\text { Ensino } \\
\text { médio }\end{array}$} & \multirow[b]{2}{*}{ EJA } & \\
\hline & Creche & $\begin{array}{c}\text { Pré } \\
\text { escola }\end{array}$ & $\begin{array}{c}\text { Anos } \\
\text { iniciais }\end{array}$ & $\begin{array}{l}\text { Anos } \\
\text { finais }\end{array}$ & & & \\
\hline 2013 & 9.002 & 12.269 & 22.876 & 2.296 & 1.032 & 494 & 47.969 \\
\hline 2014 & 9.568 & 11.959 & 25.170 & 2.043 & 1.076 & 290 & 50.106 \\
\hline 2015 & 10.295 & 12.223 & 25.732 & 1.792 & 978 & 283 & 51.303 \\
\hline
\end{tabular}

Fonte: com base em dados do Instituto Nacional de Estudos e Pesquisas Educacionais Anisio Teixeira (INEP, 2017). 
Nesse contexto, constituiu-se a Divisão de Educação Especial (DEE), composta por duas seçóes: Seção de Apoio Multidisciplinar e Seção de Apoio à Educação Especial. A primeira conta com o trabalho de 18 profissionais (sete psicólogos, quatro terapeutas ocupacionais, dois assistentes sociais, um fisioterapeuta e quatro fonoaudiólogas), com o objetivo de "constituir uma estrutura de apoio aos estudantes com Necessidades Educacionais Especiais, sua família, professor-escola e comunidade, promovendo autonomia e participação efetiva, a fim de construir oportunidades educativas e socioemocionais" (SOROCABA, 2016). O fluxo do trabalho tem início na demanda da região quando a equipe escolar, por meio de um relatório, solicita a intervenção da equipe multidisciplinar para realização da reuniāo AME e para a construção dos planos de ações. A Seção de Apoio à Educação Especial se organizou com o Atendimento Educacional Especializado, que ocorre nas 33 salas de recursos multifuncionais e que conta com os profissionais de apoio.

Os profissionais de apoio são cuidadores, estagiários, intérpretes de Língua Brasileira de Sinais (Libras) e segundo professor (professor especialista em sala de aula). Somam 131 cuidadores terceirizados, com formação no ensino médio, e um curso de cuidador; 185 estagiários, que são estudantes de pedagogia e participam da organização não governamental Centro de Integração Empresa Escola (CIEE); três intérpretes de

\section{Tabela 6}

Número de matrículas na educação especial da rede municipal no período de 2013 a 2015.

\begin{tabular}{|c|c|c|c|c|c|c|c|}
\hline \multirow{3}{*}{ Ano } & \multicolumn{6}{|c|}{ Ensino regular } & \multirow{3}{*}{ Total } \\
\hline & \multicolumn{2}{|c|}{ Educação infantil } & \multicolumn{2}{|c|}{ Ensino fundamental } & \multirow{2}{*}{$\begin{array}{c}\text { Ensino } \\
\text { médio }\end{array}$} & \multirow[b]{2}{*}{ EJA } & \\
\hline & Creche & $\begin{array}{c}\text { Pré } \\
\text { escola }\end{array}$ & $\begin{array}{c}\text { Anos } \\
\text { iniciais }\end{array}$ & $\begin{array}{l}\text { Anos } \\
\text { finais }\end{array}$ & & & \\
\hline 2013 & 68 & 96 & 249 & 23 & 8 & 9 & 453 \\
\hline 2014 & 61 & 112 & 288 & 21 & 8 & 7 & 497 \\
\hline 2015 & 43 & 111 & 304 & 22 & 7 & 11 & 503 \\
\hline
\end{tabular}

Fonte: com base em dados do Instituto Nacional de Estudos e Pesquisas Educacionais Anisio Teixeira (INEP, 2017). 
Libras terceirizados com formação específica e três segundos professores contratados por determinação de ordem judicial.

\section{CONSIDERAÇÕES FINAIS}

Em consideração a apresentação dos marcos políticos e históricos da rede municipal, podemos confirmar que esse processo constitutivo esteve marcado por desafios que perpassaram os campos das esferas pessoais (concepçóes, interesses, resistências), econômicas (falta de recursos, altos investimentos com assessorias externas), físicas (acessibilidade) e ideológicas. Destarte, confirma-se que cada período possui características peculiares de permanências e rupturas.

Também se evidencia que esse processo constitutivo de políticas para a educação especial revelou avanços com relação às ações desenvolvidas pelos profissionais da Secretaria Municipal da Educação em seus projetos governamentais, apresentando movimentos fundamentais na constituição de políticas de garantia do direito à educação. Entretanto, esses projetos governamentais não possuem raízes em um projeto de políticas públicas, o que revela que o contexto de prática está além do contexto de produção de leis do município.

Diante dessas consideraçóes, podemos afirmar que a rede municipal de educação enfrentou grandes desafios nas próprias produçóes do conhecimento para a efetivação das ações desenvolvidas, tendo como fundamentação as normatizaçôes e orientaçôes de âmbito internacional e nacional. Porém, não instituiu uma política pública municipal para a garantia da permanência dos direitos conquistados, o que faz com que permaneça em aberto a possibilidade de rupturas. Assim, ao se observar o ciclo de políticas descrito por Ball, há se encaminhar o enfrentamento a algumas regularidades da política nacional, subnacional e local, isto é, não somente identificar os problemas políticas que se configurarão como pauta das políticas públicas, mas assegurar a sua efetivação e continuidade. Reside, aí, o ponto nodal que por vezes inviabiliza ou torna a implementação do direito numa dimensão morosa e excludente. Gargalo ainda a ser debatido e encaminhado para a efetivação do direito à educação especial sem reducionismos. 


\section{REFERÊNCIAS}

BALL, S.J. Diretrizes Políticas Globais e Relações Políticas Locais em Educação. Currículo sem Fronteiras, v. 1, n. 2, p. 99-116, jul./dez. 2001. Disponível em: <http://www.curriculosemfronteiras.org/volliss2articles/ball.pdf>. Acesso em: 15 jun. 2018.

BALL, S.J.; MAINARDES, J. Políticas Educacionais: questóes e dilemas. São Paulo: Cortez, 2011.

CAIADO, K.R.M.; GONCALVES, T.G.L.; TELLES, R.T.G.; MACALLI, A.C. Deficiência e desigualdade social: o recente caminho para a escola. Caderno Cedes, Campinas, v. 34, n. 93, p. 241-260, 2014. Disponível: <http://www.scielo.br/pdf/ ccedes/v34n93/0101-3262-ccedes-34-93-0241.pdf>. Acesso em: 15 jun. 2018.

GÓES, R.S. Escolarização de alunos com deficiência intelectual: as estatísticas educacionais como expressão das políticas de educação especial no Brasil. Tese (Doutorado em Educação) - Pontifica Universidade de São Paulo, São Paulo, 2014. Disponível em: <https://tede2.pucsp.br/bitstream/handle/10445/1/ Ricardo\%20Schers\%20de\%20Goes.pdf $>$. Acesso em: 15 jun. 2018.

INSTITUTO BRASILEIRO DE GEOGRAFIA E ESTATÍSTICA (IBGE). Censo 2010. Brasil: IBGE, 2010. Disponível em: shttps://www.ibge.gov. br/estatisticasnovoportal/sociais/populacao/9662-censo-demografico-2010. html? =\&t=microdados $>$. Acesso em: 15 jun. 2018.

INSTITUTO NACIONAL DE ESTUDOS E PESQUISAS EDUCACIONAIS ANÍSIO TEIXEIRA (INEP). Censo escolar da educação básica 2016: notas estatísticas. Brasil: INEP, 2017. Disponível em: $\leq$ http://download.inep.gov. br/educacao basica/censo escolar/notas estatisticas/2017/notas estatisticas censo escolar da educacao basica 2016.pdf>. Acesso em: 15 jun. 2018.

LAPLANE, A.L.F.; CAIADO, K.R.M.; KASSAR, M.C.M. As relaçóes públicoprivado na educação especial: tendências atuais no Brasil. Teias, Rio de Janeiro, v. 17, n. 46, p. 40-55, 2016. Disponível em: shttp://www.e-publicacoes.uerj. br/index.php/revistateias/article/viewFile/25497/18546>. Acesso em: 15 jun. 2018. http://doi.org/10.12957/teias.2016.25497

MACALLI, A.C. A educação especial no município de Boa Esperança do Sul SP: uma análise das matrículas de alunos com deficiência no ensino regular. Dissertação (Mestrado em Educação) - Universidade Federal de São Carlos, São Carlos, 2013. Disponível em: <https://repositorio.ufscar.br/bitstream/handle/ ufscar/8929/DissACM.pdf?sequence=1>. Acesso em: 15 jun. 2018. 
MELETTI, S.M.F.; RIBEIRO, K. Indicadores Educacionais sobre a Educação Especial no Brasil. Caderno Cedes, Campinas, v. 34, n. 93, 2014. Disponível em: <http://www.scielo.br/pdf/ccedes/v34n93/0101-3262-ccedes-34-93-0175. pdf $>$. Acesso em: 15 jun. 2018.

PATTO, M.H.S. A produção do fracasso escolar: histórias de submissão e rebeldia. São Paulo: Casa do Psicólogo, 1999.

PEREZ, E.C.M.F. Caminhos de uma Educação Humanista. In: MANTOÁN, M.T.E. (Org.). Caminhos pedagógicos da inclusão. São Paulo: Mennon, 2001. p. 47-98.

PÚBLIO, P.L.R. Politicas de Educação Especial no município de Sorocaba, de 1988 a 2012. Dissertação (Mestrado em Educação) - Universidade Federal de São Carlos, Sorocaba, 2016. Disponível em: shttps://repositorio. ufscar.br/bitstream/handle/ufscar/7916/P\%c3\%9aBLIO Patricia 2016. pdf?sequence $=1$ \&isAllowed $=\mathrm{y}>$. Acesso em: 15 jun. 2018.

SANTOS, F.A. Cidade Educadora e escola cidadã na cidade contemporânea. Dissertação (Mestrado em Educação) - Universidade de Sorocaba, Sorocaba, 2009.

SAVIANI, D. Vicissitudes e perspectivas do direito à educação no Brasil: abordagem histórica e situação atual. Educação \& Sociedade, v. 34 n. 124, 2013. Disponível em: <http://www.scielo.br/pdf/es/v34n124/06.pdf>. Acesso em: 15 jun. 2018.

SOROCABA. Implantação das salas de recursos multifuncionais. Sorocaba, 2010. Disponível em: <http://educacao.sorocaba.sp.gov.br>. Acesso em: 2 maio 2014.

. Lei no 3.601, de 14 de junho de 1991. Dispóe sobre atendimento educacional especializado aos portadores de deficiências físicas e mentais. Sorocaba, 1991. Disponível em: <https://leismunicipais.com.br/sistema-leis>. Acesso em: 15 jun. 2018.

. Lei $n^{0} 5.413$, de 1997. Estabelece normas para o ingresso de pessoas portadoras de deficiências na rede municipal de ensino. Sorocaba, 1997. Disponível em: $\leq$ https://leismunicipais.com.br/sistema-leis $>$. Acesso em: 15 jun. 2018.

- Proposta de Setorização do Centro de Educação em Educação Dom José Lambert. Sorocaba, 2013. Disponível em: <http://educacao.sorocaba.sp.gov. br>. Acesso em: 2 maio 2014.

Propostas de açôes para o ano de 2008. Sorocaba: Instituto Paradigma, 2008. Disponível em: shttp://educacao.sorocaba.sp.gov.br . Acesso em: 2 maio 2014.

. Relatório de açōes entre SEDU, CRE e Instituto Paradigma. Sorocaba, 2011. Disponível em: <http://educacao.sorocaba.sp.gov.br $>$. Acesso em: 2 maio 2014. 
- Relatório de Processos de trabalho - macroprocesso - Itinerância. Sorocaba: Instituto Paradigma, 2009. Disponível em: shttp://educacao. sorocaba.sp.gov.br>. Acesso em: 2 maio 2014.

Relatório do Instituto Paradigma. Sorocaba, 2012. Disponível em: <http://educacao.sorocaba.sp.gov.br $>$. Acesso em: 2 maio 2014.

Relatório do trabalho desenvolvido no Centro de Referência em Educação. Sorocaba: Divisão de Educação Especial, 2016. Disponível em: $\leq$ http:// educacao.sorocaba.sp.gov.br>. Acesso em: 9 maio 2016.

\section{NOTAS}

1. Em 1995, Mario Covas assumiu o governo do estado e o mesmo partido político (PSDB) governa desde essa data.

2. Instituto Paradigma é uma Organização da Sociedade Civil de Interesse Público (OSCIP), criada no ano de 2003. Fonte: <www.iparadigma.org.br/o-instituto>. Acesso em: 18 abr. 2016.

Recebido em 15 de maio de 2018.

Aprovado em 02 de agosto de 2018. 